- Provides an understanding of disability in the UK.

- Discusses responsibilities under the Disability Discrimination Act both as an employer and as a service provider

- Comments on what alterations to your service may reasonably be expected by you to comply with the Disability Discrimination Act.

\title{
Disability Part 1: The Disability Discrimination Act (1995) - implications for dentists
}

\author{
A. J. Merry ${ }^{1}$ and D. M. Edwards ${ }^{2}$
}

The Disability Discrimination Act (1995) (DDA) aims to end the discrimination which many disabled people face in their dayto-day lives. ${ }^{1}$ But how many dentists are aware of their responsibilities under this Act? Dentists are already bound by Parts I and II of the DDA, but Part III, which is due to come into effect in 2004, and which is concerned with physical alterations to premises, has potentially profound implications for many in dental practice. Health Authorities in Merseyside, in the North West of England have been exploring ways in which access to dental care for disabled people can be improved. In this paper, the first of a series of three, we outline the DDA and how it affects dentists in general practice.

\section{MEDICAL AND SOCIAL MODELS OF DISABILITY}

Traditionally, an individual's 'medical' impairment has been seen as the disabling factor (the medical model of disability). However, many disabled people prefer to view disability in terms of the social model of disability. In this model a wheelchair user is disabled because, for example, a narrow door prevents access to a service rather than just because of the disorder which has resulted in them using a wheelchair. Although the DDA defines disability in terms of the medical model, its emphasis on making services accessible is in line with the social model.

\section{WHO IS DISABLED?}

The Disability Discrimination Act defines a disabled person as:
${ }^{1}$ Specialist Registrar in Dental Public Health $2^{2 *}$ Director of Public Health, North Liverpool Primary Care Trust, Newhall Campus, Longmoor Lane, Liverpool L10 1LD

*Correspondence to: Dympna Edwards

E-mail:dympna.edwards@northliverpoolpct.nhs.uk

\section{Refereed Paper}

Received 16.01.02; Accepted 23.05.02

๑) British Dental Journal 2002; 193: 199-201
'A person who has or has had a physical or mental impairment which has a substantial and long-term adverse effect upon his or her ability to carry out normal day-to-day activities.'

Mental illnesses and learning difficulties are covered by the DDA. Some injuries (eg back injuries, repetitive strain injury); medical problems (eg epilepsy, cancer, diabetes, AIDS); stress-related problems and facial disfigurements are also included depending on the extent to which the individual is affected. People who have been disabled in the past have rights under the DDA eg a person with a history of mental illness.

\section{Jargon}

The language around disability is continually changing and phrases commonly used 20 years ago would cause offence now. Although not everyone will be in favour of political correctness it is important to be aware of people's sensitivities. Table 1 lists a few phrases currently in use or out of use. If in doubt, asking the patient how they would describe themselves is often a good way forward.

Impairment relates to the person's condition (eg mobility impairment). This may lead to a disability, which is an inability to do something (eg climb stairs). The barriers in society can make this handicapping (eg a dental practice located up some steps with
Table I Phrases that are in and out of use around disability

\begin{tabular}{ll}
\hline IN USE & OUT OF USE \\
\hline Disabled person/ people & The disabled \\
\hline Impairment & $\begin{array}{l}\text { Handicap (literally 'cap in hand') } \\
\text { Invalid (literally - 'in-valid') }\end{array}$ \\
\hline Person with a learning difficulty & Mentally handicapped \\
\hline Wheelchair user & Wheelchair bound \\
\hline Cerebral palsy & Cripple \\
\hline Down's Syndrome & Spastic \\
\end{tabular}


no ramp). For example, a person who is deaf (hearing impairment) is not able to use a conventional telephone. If a text phone or videophone is available then they are able to use a telephone and are not disabled in their communication. However, if no text or video phones are available then the person is disabled in this respect and this can lead to isolation and may handicap the person in their life.

\section{How many disabled people are there?}

In Great Britain there are around 8.5 million disabled people of whom around 6.5 million are of working age. ${ }^{2}$ It is estimated that around $85 \%$ of the population will become impaired at some time in their lives. The vast majority of disabled people live in the community with just under 7\% living in institutions. One in four families has a member who is disabled and almost 5.7 million people ( 1 in 8) care for an elderly or disabled relative. ${ }^{3}$ By excluding disabled people a practice may lose a large number of other patients who are family members or carers.

There is a common misconception that 'disabled' always means 'wheelchair user.' In fact, less than $5 \%$ of disabled people are permanent wheelchair users. Nationally there are around 700,000 wheelchair users and about $50 \%$ of them use their wheelchair only on a temporary basis.

\section{Age differences}

The incidence of disability increases with age. Eleven per cent of 16-24 year olds are disabled compared with $33 \%$ of $50-65$ year-olds. ${ }^{2}$

\section{Regional differences}

There are regional differences in numbers of disabled people: for example Wales and the North East of England have higher proportions of disabled people compared with the East and South East of England. ${ }^{2}$

\section{Qualifications}

Disabled people are less likely to have qualifications than non-disabled people. In the working-age population, 30\% of disabled people have no qualification (compared with $14 \%$ of non-disabled people) and only $7 \%$ have a degree level qualification (compared with $14 \%$ of non-disabled people). ${ }^{2}$ Disabled people are half as likely to be in employment as non-disabled people (47\% compared with $81 \%$ ). ${ }^{2}$ Furthermore, disabled people who are in employment earn, on average, 10\% less than their non-disabled colleagues. ${ }^{2}$

\section{THE DISABILITY DISCRIMINATION ACT}

The Disability Discrimination Act (1995) gives disabled people rights in the areas of:

\section{Table 2 Parts I-III of the Disability Discrimination Act 1995}

\section{Part I}

Since 1996 It has been unlawful to treat a disabled person less favourably than anyone else for a reason related to their disability.

Part II

Since 1999 Service providers have had to make reasonable adjustments for disabled people e.g. providing extra help or making changes in the way they provide their services.

Part III

From 2004 Service providers have to make reasonable adjustments to the physical features of their premises to overcome any physical barriers to access.

- Access to goods, facilities and services

- Employment

- Buying or renting land or property.

It is being phased in over a period of years with both employment rights and access to services (Table 2). Dental practices need to ensure that they are complying with each part of the Act as it comes into effect.

All organisations and individuals providing services, facilities or goods to the public (currently excluding education and transport) have responsibilities under the DDA. The Act applies however large or small the organisation and whether a service is paid for or provided free of charge. General dental practices, community dental service clinics and hospital dental service clinics are all included.

\section{HOW DOES THE DDA APPLY TO DENTISTS AS SERVICE PROVIDERS?}

Parts 1 and 2 are already in place.

\section{Part I}

Since December 1996 it has been unlawful to treat disabled people less favourably than other people for a reason related to their disability. This would include refusal to provide a service or providing a worse service.

\section{For example:}

A dental practice near to a day-centre for people with learning difficulties refuses to accept clients of the day-centre as patients as it claims that they upset other patients.

This is discrimination on the basis of disability and is illegal.

\section{Part II}

Since October 1999, service providers have been expected to make reasonable adjustments where it is impossible or unreasonably difficult for a disabled person to use a service in three areas:

a) By changing policies, procedures and practices (eg producing leaflets in large print or having a flexible approach),

\section{For example:}

A dental practice has a policy of not allowing dogs into the practice. It would be unlawful not to change this policy in order to allow a blind person to be accompanied by a guide dog.

b) By providing an auxiliary aid or service if that would enable or make it easier for a disabled person to use their services. Auxiliary aids include pieces of equipment such as a text phone or an induction loop. Auxiliary services might also include extra help from staff or hiring a British Sign Language interpreter.

\section{For example:}

A practice could use a personal computer to produce information in large print for a patient who is partially sighted and make appointments for a deaf person using a textphone. These would be reasonable adjustments.

c) By providing a reasonable alternative method of providing the service where this is prevented or made unreasonably difficult by a physical feature.

\section{For example:}

A man who is a permanent wheelchair user is unable to get into a practice because of steps. It would be reasonable to offer a home visit for simple procedures and it may be reasonable to have an arrangement with a more accessible practice for procedures that could not be carried out on a domiciliary basis.

These requirements are already in place. The requirements with respect to physical barriers will change in 2004 with the introduction of Part III.

\section{Part III}

By 2004, service providers will have been expected to make reasonable adjustments, where necessary, to the physical features of their premises to overcome physical barriers to access in the built environment.

Possible adjustments might include widening a doorway, lowering part of a reception desk, providing a variety of styles of chair in the waiting room (different heights, with and without armrests), installing an accessible toilet or installing a ramp. 
There will be some exclusions eg listed buildings, but new buildings are likely to be expected to comply. ${ }^{4}$ Minimum access standards for buildings are set out in The Building Regulations 1991 Approved Document M ('Part M'), ${ }^{5}$ but these may not be sufficient to ensure total access eg a 'Part M' standard doorway may not be wide enough for all wheelchair users or someone with a guide-dog.

\section{WHAT IS MEANT BY 'REASONABLE ADJUSTMENTS'?}

The concept of reasonableness is very important to the DDA and any necessary changes will be as much about attitudes, approach and flexibility as about the built environment. It will not be clear how the term 'reasonable adjustment' will be interpreted and how strictly Part III of the DDA will be enforced until cases have been tried at law.

The Disability Rights Commission advises that dental practices will be expected to:

- Undergo an access audit of their premises to identify barriers to access and to determine the extent and feasibility of any necessary alterations

- Implement any alterations if it is 'reasonable' to do so.

\section{Examples of how the term 'reasonableness'} is likely to be interpreted:

- It may not be reasonable to expect a practice to routinely provide practice leaflets in Braille, - but it would be reasonable to provide them in large print and to be prepared to read them out to a partially sighted patient.

- It may not be reasonable for all practice staff to be fluent in British Sign Language (BSL), - but it would be reasonable to expect one member of staff to have some deaf equality training and/or to communicate in writing with a deaf person.

- It may not be possible to install a ramp or lift - but it might be reasonable to install a handrail to help patients climb stairs and/or it might be reasonable to install a stair lift.

It is likely that disabled people will increasingly demand the same access to dental care as non-disabled people and that they will expect to receive this alongside non-disabled people in a general practice setting.

\section{HOW THE DDA APPLIES TO DENTISTS AS EMPLOYERS}

Employers with 15 or more employees (each part-timer counts as a separate individual employee) are expected to make reasonable adjustments to accommodate the needs of disabled employees. This applies to all aspects of employment from selection, promotion and training through to dismissal and redundancy. This applies even if there are no disabled employees as an employee may become disabled and/or a disabled person may apply if a post is advertised. This is likely to include practices with less than 15 employees in the future. Funding is available from the 'Access to Work' scheme to make workplaces accessible for a disabled employee (either a new or existing employee). This would have additional benefits in making the service more accessible for patients.

\section{EXEMPTIONS FROM THE DDA}

There are a few circumstances where it may not be possible to give disabled peo- ple exactly the same service as other people and where exemptions may be made, however these are unlikely to apply in dental practice.

\section{CONCLUSION}

Dentists need to be aware of their responsibilities under the Disability Discrimination Act (1995) both as employers and providers of services. By 2004 dental practices will need to have made reasonable physical adjustments to their premises to overcome barriers to access. The Disability Rights Commission advises that dental practices undergo an access audit to inform any alterations. Barriers to access include both physical obstacles and lack of awareness. Access can often be improved at little or no cost. Where physical alterations to practice buildings are necessary for a dental practice to comply with Part III of the Disability Discrimination Act this can be planned for within practice developments.

1. The Disability Discrimination Act 1995, a guide for everybody. London: Department for Education and Employment Publication Number: DL160 revised edition.

2. Change by advice, conciliation and legal enforcement. Disability Rights Commission Strategic Plan 2001 2004. Publication Reference: DRC-POL/P/01/1English.

3. National Strategy for Carers. London: Department of Health , 2001 available at: www.carers.gov.uk

4. Improving access for disabled patients. BDA News 2001;14:34.

5. Access and facilities for disabled people. The Building Regulations 1991 Approved Document M. The Stationery Office, London: Department of the Environment, Transport and the Regions, 1999. 